\title{
Chemical composition, antioxidant and antisalmonella activity of Mangifera indica L. flower and seed kernel extracts
}

\author{
${ }^{*}$ Vilas A. Kamble ${ }^{1}$, Dipali O. Somkuwar ${ }^{1}$ and Sushilkumar J. Wankhade ${ }^{2}$ \\ ${ }^{1}$ Department of Microbiology, Adarsha Science, J.B. Arts and Birla Commerce Mahavidyalaya Dhamangaon Rly. - 444709 (MS) India \\ ${ }^{2}$ Department of Microbiology, Ghulam Nabi Azad Arts, Commerce and Science College, Barshitakli-444401, Dist. Akola (MS) India
}

\begin{abstract}
The extracts obtained from flower and seed parts of Mangifera indica L. were investigated for antioxidant and antisalmonella activities Disc diffusion assay and broth macrodilution method were used to determine the antisalmonella activity. However, DPPH assay used to determine antioxidant activities of petroleum ether, chloroform, acetone and ethanol extracts of flower and seed kernel of Mangifera indica L. The mineral content of different parts of Mangifera indica L. was determined using ICP-OES method. Seed kernel and flower were found to be the rich source of Fe with the concentration of 660.50 and $221.75 \mu \mathrm{g}$ per gram of dry weight. The antioxidant activity of the extracts was determined by DPPH free radical scavenging method. The petroleum ether extract of flower and ethanol extract of flower exhibited the most significant antisalmonella activity with the lowest MIC value of $8 \mathrm{mg} / \mathrm{ml}$. The highest antioxidant activity was recorded in petroleum ether seed kernel and chloroform flower extract with the percentage inhibition of $86.64 \pm 2.49$ and $79.80 \pm$ 1.28 , respectively. Among all the tested combinations chloroform flower and ethanol seed kernel extracts showed greater synergistic effect along with tetracycline against Salmonella typhi isolates. Four different compounds with dual property of antioxidant and antisalmonella were isolated from the petroleum ether seed kernel and acetone flower extracts using thin layer chromatography. GC-MS analysis of acetonic flower extract showed the presence of 1, 2-Benzenedicarboxylic acid, isodecyl octyl ester (Synonym: Phthalic acid). Compounds Oleic acid and eicosyl ester were found in petroleum ether seed kernel extract. The present study revealed that identified compounds are responsible for exhibiting antioxidant and antisalmonella activities in flower and seed kernel. These findings may justify the conventional use of Mangifera indica L. in the treatment of typhoid fever.
\end{abstract}

Key Words: Mangifera indica L., Antioxidant, Antisalmonella, Salmonella typhi, synergism, mineral.

\section{INTRODUCTION}

Typhoid fever is a serious public health problem in developing countries (Crump et al., 2004). Recent studies have shown that the incidence of typhoid fever is highest in children and young adults (WHO, 2007). In India most common types of infective agents responsible for enteric fever have been reported as Salmonella enterica serovar Typhi and Paratyphi A (Jesudason and John, 1992). Effective treatment for typhoid fever was been a great challenge in scientific community. Numerous antibiotics are used against typhoid fever including sulphademidine, nalidixic acid, ampicillin, chloramphenicol, $\beta$ - lactams, gentamicin, ciprofloxacin, aminoglycosides and fluoroquinolones (Kadhiravan et al., 2005; Girgis et al., 1999). Development of antibiotic resistance among pathogen is primarily concerns with the increasing failure rate of antibiotics therapy and high mortality (Davies and Davies, 2010). The emergence of multidrug resistance in bacterial diseases to the conventional antibiotics is a life threatening situation and has been reported all over the world. The development rate of novel antimicrobial drugs has leisurely behind whereas the prevalence rate of resistance has increased astronomically (Hugo and Russell, 1984). Since, last two decades South and South-east Asia have experienced the emergence and extend of multidrug resistance among salmonellae to the conventional antityphoid drugs including trimethoprimsulfamethoxazole, ampicillin and chloramphenicol (Chandel et al., 2000; Rowe et al., 1997).

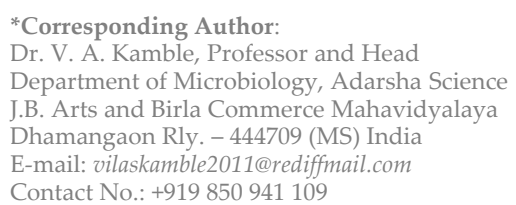

Plant based resistance modifying agents along with antibiotics may provide stable platform in tackling multiple drug resistance (MDR) among pathogen (Mandal et al., 2012). Plant may provide natural source of antimicrobial drugs that will provide novel compounds that may be employed in controlling MDR infections globally (Willcox et al., 2004; Khan et al., 2009). Many researchers have been conducted several studies on medicinal plants to know the different aspects of phytochemical constituents and their antimicrobial potentials and used as an alternative treatment of drug resistant pathogens to synthetic drugs.

Antioxidants are the chemical components with the capacity of scavenging free radicals (Tsuda et al., 1996). Compounds like carotenoids, ascorbic acid, tocopherol, flavonoids, and polyphenols, have been well documented for their antioxidant properties, antimicrobial activity, immunity booster, anti-aging, cosmetics (Wang et al., 2011; Visnja et al., 2013). Natural antioxidants are presently touching widespread attentions of medicine and nutrition due to their significant therapeutic importance on various diseases caused by free radicals (Wang et al., 2011; Emine and Salih, 2010). The potential toxicity of some synthetic antioxidants, however, has intensified research efforts to discover and utilize antioxidants from natural sources such as medicinal plants, fruits and vegetables (Kurahashi et al., 2009; Li et al., 2014).

In the current situation, there is a need of searching and improvement of novel plant based medicine with greater bioactiveness and low side effects (Essawi and Srour, 2000). Plant based antimicrobials have vast medicinal potential and their verified effectiveness in the treatment of various infectious diseases have been documented. The medicinal properties of plants without side effect could be a better alternative to synthetic drugs (Iwu et al., 1999). 
Mangifera indica L. (Mango) ever green tree which is supposed to be a native of Asia and is found greatly cultivated in India (Emeruwa, 1991). Traditionally the mango plant has medicinal applications. In the treatment of typhoid fever, dysentery, diarrhea, sore throat infection and gastrointestinal tract disorder, the infusion of Mangifera indica $\mathrm{L}$. leaves alone and in combination with Citrus sinensis is commonly used in countries like India and Nigeria (Owuor et al., 2002; Ledesma et al., 2002). Mangifera indica contain alkaloids and glycosides which are of great importance pharmacologically (Fernandez Ponce et al., 2013; Madunagu et al., 1990). Seed kernel of mango is a good source of phenolic compounds and stable fat rich in saturated fatty acids. Consequently, there is a growing demand of seed kernel in industries to utilize it as a good quality source of natural antioxidants and lipid (Arogba, 2000). The presence of phytosterols, polyphenols, sesquiterpenoids and microelements (copper, zinc and selenium) in Mangifera indica $L$. seed kernel is primarily responsible for exhibiting antioxidant properties (Schiber et al., 2003). Documented research conferred the Mangifera indica for its medicinal ability.

In this study, in vitro evaluation of Mangifera indica L. for antisalmonella and antioxidant activity is the first step towards achieving the goal for developing eco-friendly management of typhoidal infection and degenerative diseases by search of new biomolecules of plant origin. It is evident from the literature that there is wide scope for screening of Mangifera indica Linn. to ascertain therapeutic importance. Considering these, different extracts of Mangifera indica $\mathrm{L}$. were screened in vitro for antisalmonella and antioxidant activity in view of finding novel anti-microbial and antioxidant agents.

\section{MATERIALS AND METHODS}

\section{Collection of plant material}

The Mangifera indica L. flower and seed kernel were collected from the Village Karla, Taluka Patur, District Akola (MS), India. The plant was authenticated at Department of Botany, Sant Gadge Baba Amravati University, Amravati (MS) India.

\section{Preparation of plant extracts}

The shade dried plant parts were ground by mechanical grinder into coarse particles using the sieve number $2000 \mu \mathrm{m}$. The ground material was filled in a bag which were made up of Whatman No. 1 filter paper and extracted with $250 \mathrm{ml}$ of solvents with rising polarity index such as petroleum ether, chloroform, acetone and ethanol in the ratio of $1: 6 \mathrm{w} / \mathrm{v}$ in a Soxhlet apparatus at $45-50^{\circ} \mathrm{C}$ until the extract was clear or colourless. Controlled conditions of temperatures were maintained to avoid loss of heat sensitive phytochemicals. The resulting extracts were concentrated in a rotary evaporator under reduced pressure at $40^{\circ} \mathrm{C}$. Dried extracts were weighed in an analytical balance. The extracted materials were stored at $4^{\circ} \mathrm{C}$ until use.

\section{Determination of Total Phenolic Content}

Different solvent extracts of Mangifera indica L. flower and seed kernel were analyzed for total phenolic content spectrophotometrically according to the Folin-Ciocalteau colorimetric method (Singleton and Rossi, 1965). The $200 \mu \mathrm{l}$ of each extract was introduced into screw cap test tubes and $1.0 \mathrm{ml}$ of Folin-Ciocalteau reagent (1:1 with water) and $1.0 \mathrm{ml}$ of sodium carbonate $(7.5 \%)$ were added. The tubes were vortexed and incubated for $2 \mathrm{hrs}$ and the absorbance was read at $726 \mathrm{~nm}$ using a spectrophotometer (Beckman,
USA). The total phenolic content was expressed as gallic acid equivalents (GAE) in milligrams per gram dry material.

\section{Determination of Total Flavonoid Content}

The total flavonoid content was determined according to the aluminium chloride colorimetric method (Lin and Tang, 2007). Each plant extracts $(2 \mathrm{ml}, 0.3 \mathrm{mg} / \mathrm{ml})$ in methanol were mixed with $0.1 \mathrm{ml}$ of $10 \%$ aluminium chloride hexahydrate, $0.1 \mathrm{ml}$ of $1 \mathrm{M}$ potassium acetate and $2.8 \mathrm{ml}$ of deionized water. After the 40 minutes incubation at the room temperature, the absorbance of the reaction mixture was determined spectrophotometrically at $415 \mathrm{~nm}$. Quercetin was used as a standard (the concentration range: 0.005 to $0.1 \mathrm{mg} / \mathrm{ml}$ ) and the total flavonoid content was expressed as milligram QE per gram of dry extracts.

\section{Mineral Analysis}

Plant parts flower and seed kernel were evaluated for major and minor mineral content by dry ash method (Huo, 2003; Wu et al., 2003) with slight modifications. Plant materials were rinsed in clean water and dried in an oven at $80^{\circ} \mathrm{C}$ for $2 \mathrm{hrs}$ and ground in a stainless steel Wiley mill to pass through a $0.85 \mathrm{~mm}$ screen. Two grams of dried homogenized sample weight in a silica crucible (previously washed by boiling with concentrated $\mathrm{HNO}_{3}$ to remove contaminant elemental traces) was incinerated in a furnace, applying the following mineralized stages to prevent mineral losses by volatilization: $90^{\circ} \mathrm{C}-250^{\circ} \mathrm{C}$ (ramp time $2 \mathrm{hrs}$, hold time $2 \mathrm{hrs}$ ); $250^{\circ} \mathrm{C}-500^{\circ} \mathrm{C}$ (temperature was gradually increased to $500^{\circ} \mathrm{C}$, hold time $0.5 \mathrm{hr} / \mathrm{ramp} 50^{\circ} \mathrm{C}$ ) and $500^{\circ} \mathrm{C}$ (hold time $4 \mathrm{hrs}$ ). After cooling, $2.5 \mathrm{ml}$ of mixture of nitric acid (65\% Suprapur Merck), hydrochloric acid (30\% Suprapur Merck) and deionized water in a ratio of 1:1:2 (v/v) was added and the solutions were vapourized. When the solutions reached $2 \mathrm{ml}$, they were transferred into a volumetric $25 \mathrm{ml}$ flask, with the final volume of $25 \mathrm{ml}$ made up with deionized water; the solutions were subsequently stored in polypropylene bottles under refrigeration. ICP multi-element standard solution IV (23 elements in diluted nitric acid) $1000 \mathrm{mg} / \mathrm{l}$ was used for calibration. Three standards were prepared with the concentration of $0.1 \mathrm{mg} / \mathrm{l}, 1 \mathrm{mg} / \mathrm{l}$ and $10 \mathrm{mg} / \mathrm{l}$. Minor mineral elements were detected by ICPOES (Cd, $\mathrm{Co}, \mathrm{Cr}, \mathrm{Cu}, \mathrm{Fe}, \mathrm{Mn}, \mathrm{Ni}, \mathrm{Pb}, \mathrm{Zn}, \mathrm{Al}$ and $\mathrm{B}$ ) using the isotopes specified (Perkin-Elmer Optima 4100DV), while major elements $\mathrm{Na}$ and $\mathrm{K}$ contents were determined by flame photometer. All the samples were analyzed in triplicate mode.

\section{Antioxidant Activity (DPPH radical scavenging assay)}

The effect of given samples on DPPH (1, 1-diphenyl-2-picrylhydrazyl) radical was estimated according to the procedure described by Von Gadowet al., (1997). Two $\mathrm{ml}$ of $6 \times 10^{-5} \mathrm{M}$ methanolic solution of DPPH were added to $50 \mu \mathrm{l}$ of a methanolic solution $\left(10 \mathrm{mg} \mathrm{ml}^{-1}\right)$ of the sample. Absorbance measurements commenced immediately. The decrease of absorbance at $515 \mathrm{~nm}$ was continuously recorded in a spectrophotometer for $16 \mathrm{~min}$. at room temperature. Methanolic solutions of pure compound (Ascorbic acid) were tested at $1 \mathrm{mg} / \mathrm{ml}$ concentration. The scavenging effect (decrease of absorbance at $515 \mathrm{~nm}$ ) was plotted against the time and the percentage of DPPH radical scavenging ability of the sample was calculated from the absorbance value at the end of $16 \mathrm{~min}$. duration as follows:

All determinations were performed in triplicate. The percentage inhibition of the DPPH radical by the samples was calculated by using following formula, 
$\left.\mathrm{IP}=\left[\left(\mathrm{Ac}_{(0)}-\mathrm{AA}_{\mathrm{A}} \mathrm{t}\right) / \mathrm{Ac}(0)\right)\right] \times 100$

Where $A_{c}(0)$ is the absorbance of the control at $t=0 \mathrm{~min}$; and $\mathrm{A}_{\mathrm{A}}(\mathrm{t})$ is the absorbance of the antioxidants at $\mathrm{t}=16$ minutes.

\section{Antisalmonella activity}

Flower and seed kernel extracts of Mangifera indica L. were examined for their possible antisalmonella activity against 50 MDR isolates of Salmonella typhi, which has been identified in our previous study (Kamble et al., 2016). The standard antibiotic disc tetracycline $(10 \mathrm{mcg})$ and sterile discs having $6 \mathrm{~mm}$ diameter were procured from Hi-Media Pvt. Ltd. Mumbai. The stocks of Salmonella typhi isolates were maintained by inoculating jet black single colony from bismuth sulphite agar on nutrient agar slants and incubated at $37^{\circ} \mathrm{C}$ for $24 \mathrm{hrs}$ and stored under refrigeration until use. The inoculum of Salmonella typhi isolates were prepared by inoculating the culture into the sterile MullerHinton broth and incubated at $37^{\circ} \mathrm{C}$ for 2 to $6 \mathrm{hrs}$ till the moderate turbidity developed. The inoculum was standardized by matching $0.09 \pm 0.01$ optical density $(\mathrm{OD})$ at 625 nm.

\section{Disc diffusion assay}

Antisalmonella activity of Mangifera indica L. extracts was performed by a disc diffusion method (CLSI, 2009). Mueller-Hinton agar plates were prepared by pouring approximately $25 \mathrm{ml}$ of sterilized medium into Petri plates to a depth of $3-4 \mathrm{~mm}$. The bacterial suspension was uniformly spread on the surface of Mueller Hinton agar plates. The sterile disc having $20 \mu \mathrm{l}$ holding capacity was impregnated with extract $(200 \mathrm{mg} / \mathrm{ml})$ and placed on the surface of medium. The stock solution of extracts $(200 \mathrm{mg} / \mathrm{ml})$ was prepared by dissolving crude extract with $5 \%$ DMSO. The plates were kept at room temperature for $2 \mathrm{hrs}$ to allow diffusion of extract and incubated at $37^{\circ} \mathrm{C}$ for $24 \mathrm{hrs}$. Zone of inhibition was measured in millimeter $(\mathrm{mm})$ scale. Tetracycline $(10 \mathrm{mcg})$ discs were included as experimental positive control and 5\% DMSO as negative control. The test was performed in triplicates. The efficacy of plant extracts was measured in terms of activity index (AI). The activity index was calculated by the following formula (Jain and Sharma, 2003).

Activity index $=\frac{\text { Inhibition zone diameter }(\mathrm{mm}) \text { of extract }}{\text { Inhibition zone diameter }(\mathrm{mm}) \text { of antibiotic }}$

On the basis of clear zone of inhibition (ZOI) results of antisalmonella activity of plant extract was categorized into four groups viz. Inactive or resistant $(\leq 12 \mathrm{~mm})$, mildly sensitive (13-15 mm), moderately sensitive (16-19 $\mathrm{mm})$, strongly sensitive $(\geq 20 \mathrm{~mm})$.

\section{Broth macrodilution assay}

Broth macrodilution assay was performed as outlined by CLSI, 2009 with some modification to determine the minimum inhibitory concentration (MIC) of plant extracts. A stock solution of plant extracts $(1024 \mathrm{mg} / \mathrm{ml})$ was prepared in 5\% DMSO and made serial two fold dilutions in range of $1-512 \mathrm{mg} / \mathrm{ml}$ in Muller Hinton broth. The plant extracts exhibiting significant inhibitory activity against clinical isolates were selected for MIC determination. The test tubes were incubated at $37^{\circ} \mathrm{C}$ for $24 \mathrm{hrs}$ without agitation and observed for the presence or absence of red coloured visible growth by adding $50 \mu \mathrm{L}$ of $0.5 \%$ TTC (Triphenyl Tetrazolium Chloride) aqueous solution (Klancnik et al., 2010). MIC was defined as the lowest concentration of plant extract that inhibited visible or viable growth. Tests were performed in duplicate and the lowest concentration of plant extract that inhibited the growth of bacteria without shaking was taken as minimum inhibitory concentration (MIC).

\section{Determination of MBC Value}

Minimum Bactericidal Concentration (MBC) values were determined by spot inoculation method. A sample was taken from the tubes without bacterial growth (including MIC) along with the control tube and spotted on Muller Hinton agar plate with the help of sterile cotton swabs. Plates were incubated for $24 \mathrm{hrs}$ at $37^{\circ} \mathrm{C}$. The $\mathrm{MBC}$ value considered as lowest concentration of plant extracts exhibited no growth after incubation.

\section{Synergistic Activity}

Synergistic activity was measured using disc diffusion method. The inhibitory activity of flower and seed kernel extracts of Mangifera indica L. was tested independently and in combination with tetracycline against 15 MDR Salmonella typhi isolates. The results antisalmonella activity of extract and antibiotic independently and in combination was calculated and categorized by fixing the scale for inhibitory activity in terms of inhibition zone diameter $(\mathrm{mm})$. The combination effect was considered as synergistic, if their joint effect was stronger than the sum of effects of the individual agents; additive, if their joint effect is equal to the sum of effect of the individual agents; and antagonistic, if their joint effect is weaker than the sum of effects of the individual agents. Synergistic activity was further categorized as partial synergistic (Enlargement of combined inhibition zone by $>1 \mathrm{~mm}$ and $<5 \mathrm{~mm}$ ) and effective synergistic activity (Enlargement of combined inhibition zone by $>5 \mathrm{~mm})$.

\section{Fractionation and isolation}

TLC was performed on a pre-coated silica gel TLC plates grade F254 (E-Merck, Darmstadt, Germany) to determine the number of compounds present in the given sample. A total of $5 \mu \mathrm{l}(1 \mathrm{mg} / \mathrm{ml})$ of sample was spotted at $1 \mathrm{~cm}$ from the bottom of silica gel plates using capillary tubes. Different solvents at various combinations and concentrations were used for metabolites profiling. The chromatogram was developed in a presaturated (eluent vapour) chromatographic chamber. The developed chromatogram was visualized under UV light ( $365 \mathrm{~nm}$ and $254 \mathrm{~nm}$ ) and iodine vapour. The Rf values of the compounds were calculated using the following formula.

$R f=\frac{\text { distance travelled by the compound }}{\text { distance travelled by the solvent front }}$

\section{TLC based Antioxidant Activity}

An aliquot of active extracts of Mangifera indica L. $(1 \mathrm{mg} / \mathrm{ml})$ was spotted onto the TLC plates. The TLC plates were developed in solvent saturated chamber with solvent systems as developing solvent system, until the solvent front reached to $1 \mathrm{~cm}$ from the top of plates. The developed TLC plates were air dried for 30 minutes and used for the detection of antioxidant compounds by DPPH spray method. The DPPH solution $(10 \mathrm{mg} / \mathrm{ml})$ was sprayed over the TLC plate and kept few minutes for drying. While drying, a pale yellow spot observed on the TLC plate in the vicinity of the dispersed compounds. The $\mathrm{Rf}$ values for the antioxidant compounds were calculated.

\section{TLC based Bioautography (Agar-Overlay method)}

The TLC bioautography was determined by agar-overlay method (Zheng et al., 2005). The TLC plate was placed in a sterile Petri plate and $20 \mathrm{ml}$ of molten Mueller Hinton Agar 
was poured into plate (Hi media, Mumbai, India), aseptically. The plates were allowed to solidify and left for two hours absorption. After which 18 hrs grown (OD adjusted 0.6) $100 \mu \mathrm{l}$ of bacterial inoculum was added on top of plate and spread using sterile L-rod spreader to prepared culture lawn. The plates were incubated at $37^{\circ} \mathrm{C}$ in a $40 \mathrm{~W}$ florescent light source $(\sim 400 \mathrm{~nm})$ for $24 \mathrm{hrs}$. The antisalmonella activity of the compound was visualized.

\section{Identification of constituents by GC-MS Analysis}

The TLC bands with the antioxidant and antisalmonella activity were scraped and dissolved in a $1 \mathrm{ml}$ methanol solvent (HPLC grade), centrifuged at $3000 \mathrm{rpm}$ for 15 minutes. The supernants was transferred to the sample tube, without disturbing the settled silica particles and used as a test sample. Sample volume of $2 \mu l$ was used for GC-MS analysis. GC-MS analysis of active fractions of Mangifera indica L. was performed using an Agilent 6890 gas chromatograph was equipped with a straight deactivated $2 \mathrm{~mm}$ direct injector liner and a $15 \mathrm{~m}$ Alltech EC-5 column $(250 \mu$ I.D., $0.25 \mu$ film thickness). A split injection was used for sample introduction and the split ratio was set to 10:1. The oven temperature program was programmed to start at $35^{\circ} \mathrm{C}$, hold for 2 minutes, then ramp at $20^{\circ} \mathrm{C}$ per minute to $300^{\circ} \mathrm{C}$ and hold for 5 minutes. The helium carrier gas was set to $2 \mathrm{ml} /$ minute flow rate (constant flow mode).

JEOL GCmate II benchtop double-focusing magnetic sector mass spectrometer working in electron ionization (EI) mode with TSS-20001 software was used for all analyses. Low-resolution mass spectra were obtained at a resolving power of 1000 (20\% height definition) and scanning from $\mathrm{m} / \mathrm{z} 25$ to $\mathrm{m} / \mathrm{z} 700$ at 0.3 seconds per scan with a 0.2 second inter-scan delay. High resolution mass spectra were acquired at a resolving power of 5000 (20\% height definition) and scanning the magnet from m/z 65 to m/z 750 at $1 \mathrm{sec}-$ ond per scan. Identification of compounds was done by matching their recorded spectra with the data bank mass spectra of NIST library V 11 provided by the instruments software.

\section{RESULTS}

\section{Quantitative Phytochemical Screening \\ Total phenolic and flavonoid content}

The results of total phenolic content and flavonoid content of Mangifera indica L. flower and seed kernel are presented in Table 1. Results of total phenolic contents are expressed as milligram GAE (Gallic Acid Equivalent) per milligram of dry extract and total flavonoid content are expressed as microgram QE (Quercetin Equivalent) per $5 \mathrm{mg}$ of dry extract. Acetone and ethanol solvents exhibited maximum capacity to extract the phenolic compounds than chloroform and petroleum ether solvents. Among all the tested extracts, ethanolic flower extract showed highest phenol content of $22.36 \pm 0.97 \mathrm{mg}$ gallic acid equivalent $/ \mathrm{mg}$ of dry sample. In contrast, PE seed kernel showed lowest phenol content of $0.27 \pm 0.07 \mathrm{mg}$ gallic acid equivalent $/ \mathrm{mg}$ of dry sample. The significant amount of TPC was also observed in extracts of acetone flower $(15.45 \pm 1.12 \mathrm{mg} \mathrm{GAE} / \mathrm{mg}$ of dry sample) and seed kernel (10.36 $\pm 1.01 \mathrm{mg}$ GAE$/ \mathrm{mg}$ of dry sample). The present study states that, petroleum ether and chloroform extracts were the poor source of phenolic compounds as compared to acetone and ethanol extracts.

Flavonoids content of the given samples was spectrophotometrically calculated and the results of acetonic seed extract showed the lowest flavonoids content of $72 \mu \mathrm{g} Q E / 5$ $\mathrm{mg}$ of dry extract. Of the eight different extracts of Mangifera indica L. studied the amount of flavonoids was found in the order of $\mathrm{AC}$ (Flower) $(341 \pm 3.61)>\mathrm{CHL}$ (Flower) $(334.33 \pm 3.51)>$ ET $($ Flower $)(180 \pm 2.0)>$ CHL (Seed kernel) $(144.33 \pm 2.08)>$ PE $($ Flower $)(78.67 \pm 2.08)>$ ET (Seed kernel) $(75 \pm 1.0)>$ AC (Seed kernel) $(72 \pm 2.0)>$ PE (Seed kernel) $(42.33 \pm 2.52)$. It was evident from the study that, among the parts of Mangifera indica L., tested flower exhibited higher TFC value than seed kernel.

\section{Mineral content}

The micro and macro-element contents $(\mathrm{Cd}, \mathrm{Co}, \mathrm{Cr}, \mathrm{Cu}, \mathrm{Fe}$, $\mathrm{Mn}, \mathrm{Ni}, \mathrm{Pb}, \mathrm{Zn}, \mathrm{Al}, \mathrm{B}, \mathrm{Na}$ and $\mathrm{K}$ ) of Mangifera indica L. flower and seed kernel showed varying degree of elemental composition and the results are presented in Table 2. The results of mineral content of Mangifera indica L. was calculated in two scale as milligram per liter $\left(\mathrm{mg} \mathrm{l}^{-1}\right)$ and microgram per gram $\left(\mu \mathrm{g} \mathrm{g}^{-1}\right)$ of plant material. The correlation study of mineral content of flower and seed kernel were found to be significant at the 0.01 level $\left(\mathrm{r}^{2}=0.998\right)$. Seed kernel from Mangifera indica L. was appeared to be rich source of iron $(\mathrm{Fe})$ with the concentration of $660.50 \mu \mathrm{g}$ $\mathrm{g}^{-1}$. The high level of lead $(\mathrm{Pb})$ content $\left(3.99 \mu^{-1} \mathrm{~g} \mathrm{~g}^{-1}\right)$ was detected in flower. The significant amount of zinc ( $\mathrm{Zn})$ was recorded in seed kernel $\left(11.81 \mu^{-1} \mathrm{~g} \mathrm{~g}^{-1}\right)$ and flower $(10.70 \mu \mathrm{g}$ $\left.\mathrm{g}^{-1}\right)$. Macro-element $\mathrm{Na}$ was recorded higher in seed kernel $\left(1181.25 \mu \mathrm{g} \mathrm{g}^{-1}\right)$, followed by flower $\left(960 \mu \mathrm{g} \mathrm{g}^{-1}\right)$. Mangifera indica L. was found to be prominent source of potassium (K) with the order seed kernel $\left(4687.50 \mu \mathrm{g} \mathrm{g}^{-1}\right)>$ flower $\left(4583.75 \mu \mathrm{g} \mathrm{g}^{-1}\right)$.

\section{Antioxidant activity}

In this study, the extracts of Mangifera indica L. flower and seed kernel were examined for their scavenging of DPPH. The results of DPPH free radical scavenging activity of Mangifera indica L. extracts are presented in Table 3. The P.E. seed kernel extract showed highest antioxidant activity of $86.64 \pm 2.49 \%$ followed by chloroform seed kernel $(84.05 \pm$ $1.61 \%)$, chloroform flower $(79.80 \pm 1.28)$, ethanol seed kernel $(73.20 \pm 0.84)$ and acetone flower $(72.85 \pm 0.76)$ extract. Overall, seed kernel extracts exhibited strong antioxidant potency as compared to flower and found to be lesser when compared with standard ascorbic acid.

\section{Antisalmonella activity}

The antisalmonella activity of flower and seed extracts of Mangifera indica L. against 50 multidrug resistant (MDR) isolates of Salmonella typhi were studied. Petroleum ether extracts were found to be most effective antisalmonella agent against MDR Salmonella typhi isolates, followed by ethanol, acetone and chloroform extracts. All 50 clinical isolates of pathogenic Salmonella typhi were found to be strongly sensitive to P.E. flower extracts. However, P.E. seed kernel extract exhibited strong inhibitory activity against $96 \%$ isolates of Salmonella typhi. Among all petroleum ether extracts of Mangifera indica L. flower exhibited maximum inhibitory activity against all the tested isolates of Salmonella typhi with the inhibition zone range of 24$34 \mathrm{~mm}$. Seed kernel extract demonstrated the inhibitory activity with considerable IZD value ranged from $19-26 \mathrm{~mm}$. Chloroform extract of flower and seed kernel was found to be inactive towards Salmonella typhi isolates.

Acetone extracts of flower showed maximum antisalmonella activity against almost all the tested isolates, with the inhibition zone diameter in the range of $15-22 \mathrm{~mm}$. However, acetone seed kernel extract demonstrated the considerable antisalmonella effect with the IZD ranging from $12-18 \mathrm{~mm}$. Among 50 Salmonella typhi isolates $78 \%$ and $100 \%$ isolates were found to be strongly sensitive to seed 
Table 1: Total phenolic and flavonoid content of Mangifera indica L. flower and seed kernel extracts.

\begin{tabular}{ccc}
\hline Extract & $\begin{array}{c}\text { Total Phenol Content } \\
\text { (mg GAE/mg of dry samples) }\end{array}$ & $\begin{array}{c}\text { Total Flavonoid Content } \\
\text { ( } \boldsymbol{\mu g} \text { QE/5mg of dry samples)* }^{*}\end{array}$ \\
\hline PE (Flower) & $5.02 \pm 0.21$ & $78.67 \pm 2.08$ \\
PE (Seed kernel) & $0.27 \pm 0.07$ & $42.33 \pm 2.52$ \\
CHL (Flower) & $1.57 \pm 0.21$ & $334.33 \pm 3.51$ \\
CHL (Seed kernel) & $1.76 \pm 0.51$ & $144.33 \pm 2.08$ \\
AC (Flower) & $15.45 \pm 1.12$ & $341 \pm 3.61$ \\
AC (Seed kernel) & $10.36 \pm 1.01$ & $72 \pm 2.0$ \\
ET (Flower) & $22.36 \pm 0.97$ & $180 \pm 2.0$ \\
ET (Seed kernel) & $0.90 \pm 0.19$ & $75 \pm 1.0$ \\
\hline
\end{tabular}

Note: PE- Petroleum ether; CHL- Chloroform; AC- Acetone; ET- Ethanol; GAE- Gallic Acid Equivalent; QE- Quercetin Equivalent; *Values are means of triplicate with standard deviations.

Table 2: Mineral composition of Mangifera indica L. flower and seed kernel.

\begin{tabular}{|c|c|c|c|c|}
\hline \multirow{2}{*}{ Elements } & \multicolumn{2}{|c|}{ Flower } & \multicolumn{2}{|c|}{ Seed kernel } \\
\hline & Concentration $(\mathrm{mg} / \mathrm{L})$ & Concentration $(\mu \mathrm{g} / \mathrm{g})$ & Concentration $(\mathrm{mg} / \mathrm{L})$ & Concentration $(\mu \mathrm{g} / \mathrm{g})$ \\
\hline $\mathrm{Cd}$ & ND & ND & ND & ND \\
\hline Co & ND & ND & ND & ND \\
\hline $\mathrm{Cr}$ & 0.05 & 0.68 & 0.13 & 1.60 \\
\hline $\mathrm{Cu}$ & 0.33 & 4.14 & 0.67 & 8.38 \\
\hline $\mathrm{Fe}$ & 17.74 & 221.75 & 52.84 & 660.50 \\
\hline $\mathrm{Mn}$ & 0.51 & 6.36 & 1.24 & 15.50 \\
\hline $\mathrm{Ni}$ & 0.06 & 0.80 & 0.09 & 1.18 \\
\hline $\mathrm{Pb}$ & 0.32 & 3.99 & 0.15 & 1.89 \\
\hline $\mathrm{Zn}$ & 0.86 & 10.70 & 0.95 & 11.81 \\
\hline $\mathrm{Al}$ & 12.98 & 162.25 & 59.82 & 747.75 \\
\hline B & 0.44 & 5.48 & 0.41 & 5.09 \\
\hline $\mathrm{Na}$ & 76.80 & 960.00 & 94.50 & 1181.25 \\
\hline $\mathrm{K}$ & 366.70 & 4583.75 & 375.00 & 4687.50 \\
\hline
\end{tabular}

Note: *Values are means of triplicates; ND - Not detected.

kernel and flower extract, respectively. The utmost inhibitory activity was observed in ethanol extracts of flower (20$24 \mathrm{~mm})$ and seed kernel $(17-24 \mathrm{~mm})$. In case of ethanol seed kernel extract $22 \%$ and $78 \%$ isolates were found to be moderately sensitive and strongly sensitive, respectively. The comparative study of antisalmonella efficacy of Mangifera indica L. extracts and standard antibiotics against Salmonella typhi isolates was studied by calculating activity index.

The P.E. extracts of flower and seed kernel exhibited highest antisalmonella effect with the activity index of 3.30 and 2.70, respectively. P.E. Flower extract demonstrated antisalmonella activity with the $\mathrm{AI}$ in the range of 1.55-3.30 and highest $\mathrm{AI}$ (3.30) was observed against ST-2 isolate. Acetonic seed kernel extract exhibited antisalmonella effect with the $\mathrm{AI}$ in the range of $0.82-1.70$ and highest $\mathrm{AI}$ value of 1.70 was recorded against ST-4, ST-31 and ST-39 isolates. Antisalmonella effect of ethanol extracts showed wide range of inhibitory activities with the activity index $>1$ against most of the tested isolates of Salmonella typhi. Ethanol flower extract also showed significant antisalmonella effect with the AI of 2.40 against ST-9 isolate.

Minimum inhibitory concentration (MIC) and Minimum bactericidal concentration (MBC)

Antisalmonella activity of Mangifera indica L. extracts checked by disc diffusion method (indirect or qualitative method) showed the effectiveness of Mangifera indica L. more or less significant against MDR Salmonella typhi isolates. The extent of antisalmonella activity was evaluated by determining MIC values. The MIC of Mangifera indica L. extracts was tested within the range of concentration from $1-512 \mathrm{mg} / \mathrm{ml}$. The results of MIC sensitivity testing of ten MDR Salmonella typhi isolates to Mangifera indica L. extracts are shown in Table 4 and 5. The range of MIC values of petroleum ether, chloroform, acetone and ethanol extracts of flower was between 8-32, 256-512, 8-32 and 8-16 mg/ml, respectively. The P.E. extract of flower showed lowest MIC/MBC value of $8 \mathrm{mg} / \mathrm{ml}$ against ST-2, ST-3, ST-5, ST-6, ST-7 and ST-10.

Acetone extract of flower showed higher antisalmonella activity with the lower MIC value ranging from 8-32 $\mathrm{mg} / \mathrm{ml}$. The isolate ST- 8 showed highest antisalmonella sensitivity towards acetonic flower extract with the lowest MIC value of $8 \mathrm{mg} / \mathrm{ml}$. However, ethanolic extract of flower exhibited second most inhibitory activity with the MIC ranging from $8-16 \mathrm{mg} / \mathrm{ml}$ after petroleum ether extract of flower. The lowest MIC value of $8 \mathrm{mg} / \mathrm{ml}$ was observed against ST-1, ST-2 and ST-7 in ethanolic extract while ST-2, ST-3, ST-5, ST-6, ST-7 and ST-10 also were found to be consistently sensitive to P.E. extract of flower with $8 \mathrm{mg} / \mathrm{ml}$ as

Table 3: Antioxidant activity of Mangifera indica L. extracts by DPPH assay.

\begin{tabular}{ccc}
\hline \multirow{2}{*}{ Extract } & \multicolumn{2}{c}{ Antioxidant activity (\%) ${ }^{*} @$} \\
\cline { 2 - 3 } & Flower & Seed kernel \\
\hline Ethanol & $54.65 \pm 1.17$ & $73.20 \pm 0.84$ \\
Acetone & $72.85 \pm 0.76$ & $21.14 \pm 0.71$ \\
Chloroform & $79.80 \pm 1.28$ & $84.05 \pm 1.61$ \\
Petroleum ether & $56.53 \pm 1.30$ & $86.64 \pm 2.49$ \\
Ascorbic acid (Stand- & & \\
ard) & \multicolumn{3}{c}{98.58} \\
\hline
\end{tabular}

Note: ${ }^{\circledR} 10 \mathrm{mg}$ sample/assay; ${ }^{*}$ values are means of triplicate with standard deviations. 
Table 4: MIC ( $\mathrm{mg} / \mathrm{ml})$ and MBC $(\mathrm{mg} / \mathrm{ml})$ of flower extracts.

\begin{tabular}{|c|c|c|c|c|c|c|c|c|c|c|}
\hline \multirow{3}{*}{$\begin{array}{c}\text { Isolate } \\
\text { No. }\end{array}$} & \multicolumn{8}{|c|}{ Flower extract } & \multirow{2}{*}{\multicolumn{2}{|c|}{$\begin{array}{c}\text { Positive control } \\
\text { Tetracycline }(\mu \mathrm{g} / \mathrm{ml}\end{array}$}} \\
\hline & \multicolumn{2}{|c|}{ P.E. } & \multicolumn{2}{|c|}{ C.L. } & \multicolumn{2}{|c|}{ A.C. } & \multicolumn{2}{|c|}{ E.T. } & & \\
\hline & MIC & MBC & MIC & MBC & MIC & MBC & MIC & MBC & MIC & MBC \\
\hline ST-1 & 16 & 16 & $>512$ & $>512$ & 16 & 16 & 8 & 8 & 10 & 10 \\
\hline ST-2 & 8 & 8 & 512 & 512 & 16 & 16 & 8 & 8 & 10 & 10 \\
\hline ST-3 & 8 & 8 & $>512$ & $>512$ & 16 & 16 & 16 & 16 & 5.0 & 5.0 \\
\hline ST-4 & 16 & 16 & 512 & 512 & 32 & 32 & 16 & 16 & 10 & 10 \\
\hline ST-5 & 8 & 8 & $>512$ & $>512$ & 16 & 16 & 16 & 16 & 5.0 & 5.0 \\
\hline ST-6 & 8 & 8 & 256 & 256 & 16 & 16 & 16 & 16 & 5.0 & 5.0 \\
\hline ST-7 & 8 & 8 & $>512$ & $>512$ & 16 & 16 & 8 & 8 & 10 & 10 \\
\hline ST-8 & 32 & 32 & 256 & 256 & 8 & 8 & 16 & 16 & 10 & 10 \\
\hline ST-9 & 16 & 16 & 256 & 256 & 16 & 16 & 16 & 16 & 5.0 & 5.0 \\
\hline ST-10 & 8 & 16 & $>512$ & $>512$ & 16 & 16 & 16 & 16 & 5.0 & 5.0 \\
\hline
\end{tabular}

Note: P.E. - Petroleum ether, C.L. - Chloroform, A.C. - Acetone, E.T. - Ethanol.

Table 5: MIC ( $\mathrm{mg} / \mathrm{ml})$ and MBC $(\mathrm{mg} / \mathrm{ml})$ of seed kernel extracts.

\begin{tabular}{|c|c|c|c|c|c|c|c|c|c|c|}
\hline \multirow{3}{*}{ Isolate } & \multicolumn{8}{|c|}{ Seed kernel extract } & \multirow{2}{*}{\multicolumn{2}{|c|}{$\begin{array}{c}\text { Positive control } \\
\text { Tetracycline }(\mu \mathrm{g} / \mathrm{ml}\end{array}$}} \\
\hline & \multicolumn{2}{|c|}{ P.E. } & \multicolumn{2}{|c|}{ C.L. } & \multicolumn{2}{|c|}{ A.C. } & \multicolumn{2}{|c|}{ E.T. } & & \\
\hline & MIC & MBC & MIC & MBC & MIC & MBC & MIC & MBC & MIC & MBC \\
\hline ST-1 & 16 & 16 & $>512$ & $>512$ & 16 & 16 & 8 & 8 & 10 & 10 \\
\hline ST-2 & 16 & 16 & $>512$ & $>512$ & 32 & 32 & 16 & 16 & 10 & 10 \\
\hline ST-3 & 8 & 8 & $>512$ & $>512$ & 64 & 64 & 16 & 16 & 5.0 & 5.0 \\
\hline ST-4 & 16 & 16 & 512 & 512 & 32 & 32 & 32 & 32 & 10 & 10 \\
\hline ST-5 & 16 & 16 & $>512$ & $>512$ & 16 & 16 & 8 & 8 & 5.0 & 5.0 \\
\hline ST-6 & 32 & 32 & 256 & 256 & 32 & 32 & 32 & 32 & 5.0 & 5.0 \\
\hline ST-7 & 16 & 16 & 256 & 256 & 16 & 16 & 8 & 8 & 10 & 10 \\
\hline ST-8 & 16 & 16 & 256 & 256 & 16 & 16 & 16 & 16 & 10 & 10 \\
\hline ST-9 & 16 & 16 & 256 & 256 & 8 & 8 & 8 & 16 & 5.0 & 5.0 \\
\hline ST-10 & 8 & 8 & 128 & 128 & 32 & 32 & 16 & 16 & 5.0 & 5.0 \\
\hline
\end{tabular}

Note: P.E. - Petroleum ether, C.L. - Chloroform, A.C. - Acetone, E.T. - Ethanol.

there MIC value. The results indicate that P.E. and ethanolic extracts of flower showed higher antisalmonella effect than acetone and chloroform extracts.

The results of MIC and MBC of seed kernel extracts of Mangifera indica L. are given in Table 5. The ethanolic extract of seed kernel displayed significant antisalmonella activity with the lowest MIC and MBC value ranging from $8-32 \mathrm{mg} / \mathrm{ml}$, followed by petroleum ether extract (8-32 $\mathrm{mg} / \mathrm{ml})$, acetone extract $(8-64 \mathrm{mg} / \mathrm{ml})$ and chloroform extract $(128-512 \mathrm{mg} / \mathrm{ml})$. In case of petroleum ether extract, seed kernel showed considerable antisalmonella activity with the lowest MIC value of $8 \mathrm{mg} / \mathrm{ml}$ against ST-3 and ST10 isolates, while MIC of $16 \mathrm{mg} / \mathrm{ml}$ was observed against ST-1, ST-2, ST-4, ST-5, ST-7, ST-8 and ST-9 isolates. Whereas chloroformic extract of seed kernel showed least antisalmonella activity with the highest MIC value ranging from 128$512 \mathrm{mg} / \mathrm{ml}$. However, highest inhibitory activity was observed in ethanolic extract of seed kernel with the lowest MIC value of $8 \mathrm{mg} / \mathrm{ml}$ against ST-1, ST-5, ST-7 and ST-9 isolates.

On the other hand acetone extract of seed kernel exhibited wide range of antisalmonella activity with the MIC value in the range of $8-64 \mathrm{mg} / \mathrm{ml}$. Acetone extract of seed kernel was found to exhibit significant antisalmonella effect with the lowest MIC and MBC value of $8 \mathrm{mg} / \mathrm{ml}$ against ST-9 isolate. Overall, the antisalmonella effectiveness of seed kernel extracts was found in the order of ethanol extract $>$ petroleum ether extract $>$ acetone extract $>$ chloroform extract. The positive control tetracycline showed antisalmonella effect with the MIC/MBC value in the range of 5- $10 \mu \mathrm{g} / \mathrm{ml}$. Tetracycline displayed less effectiveness with the MIC value of $10 \mu \mathrm{g} / \mathrm{ml}$ against ST-1, ST-2, ST-4, ST-7 and ST-8 isolates, while more effectiveness was observed with low MIC value $5 \mu \mathrm{g} / \mathrm{ml}$ against ST-3, ST- 5 . ST-6, ST-9 and ST-10 isolates.

\section{Synergistic activity}

The eight combinations of four different solvent extracts (petroleum ether, chloroform, acetone and ethanol) of flower and seed kernel with tetracycline exhibited wide range of interaction effects as antagonistic, additive and synergistic (Table 6). The combination of P.E. flower extract and tetracycline demonstrated considerable antisalmonella activity against ST-7 and ST-9 by showing partial synergism with the increasing zone of inhibition by $4 \mathrm{~mm}$ and 2 $\mathrm{mm}$, respectively; but additive effect was observed against ST-8. Seed kernel extract exhibited good level of inhibitory activity enhancing effect against Salmonella typhi isolates with the inhibition zone in the range of $20-24 \mathrm{~mm}$ alone, which was increased to $24-45 \mathrm{~mm}$ in combination with tetracycline. Surprisingly, P.E. seed kernel extracts showed more synergistic effect as compared to P.E. flower extract. Chloroform flower extract did not show any antisalmonella effect when used independently, while combination with tetracycline showed significant interactions by showing synergistic effect against more than $45 \%$ tested isolates.

Overall, chloroform extracts in combination with tetracycline demonstrated extraordinary synergism which was found to be more significant as compared to all the tested combinations of Mangifera indica L. extracts with antibiotic tetracycline. The acetone flowers extract demonstrated significant antisalmonella activity against most of the tested isolates alone and even after combination with tetracycline no significant increase in the inhibition zone diameter was recorded. Acetone seed kernel extract alone showed inhibitory activity with the IZD in the range 
Table 6: Combination effect of Mangifera indica L. extracts in combination with standard antibiotics.

\begin{tabular}{|c|c|c|c|c|c|c|c|c|c|c|c|c|c|c|c|c|}
\hline \multirow{2}{*}{$\begin{array}{l}\vec{E} \\
\frac{2}{0} \\
\dot{8}\end{array}$} & \multirow[b]{2}{*}{ Extract } & \multicolumn{15}{|c|}{ Diameter of Zone of Inhibition $(\mathrm{mm})^{*}$ on different isolates } \\
\hline & & 站 & 竝 & $\stackrel{m}{n}$ & $\frac{\pi}{\omega}$ & 菅 & $\stackrel{p}{\stackrel{H}{H}}$ & 点 & $\begin{array}{l}\infty \\
\substack{1 \\
\omega}\end{array}$ & 定 & 常 & 晃 & $\begin{array}{l}\text { 尚 } \\
\stackrel{5}{\omega}\end{array}$ & $\frac{m}{\stackrel{1}{n}}$ & $\stackrel{+}{H}$ & 号 \\
\hline \multirow{4}{*}{ 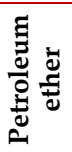 } & FL & 32 & 31 & 32 & 29 & 31 & 31 & 30 & 29 & 31 & 32 & 31 & 29 & 31 & 30 & 31 \\
\hline & FL+TE & 43 & 38 & 45 & 37 & 28 & 41 & 47 & 39 & 49 & 37 & 41 & 34 & 41 & 42 & 39 \\
\hline & SK & 24 & 22 & 23 & 21 & 23 & 21 & 20 & 24 & 23 & 22 & 23 & 21 & 22 & 23 & 24 \\
\hline & $\mathrm{SK}+\mathrm{TE}$ & 28 & 27 & 37 & 31 & 24 & 25 & 25 & 41 & 38 & 29 & 27 & 39 & 33 & 37 & 45 \\
\hline \multirow{4}{*}{ 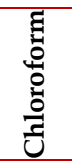 } & FL & 0 & 0 & 0 & 0 & 0 & 0 & 0 & 0 & 0 & 0 & 0 & 0 & 0 & 10 & 0 \\
\hline & FL+TE & 11 & 12 & 14 & 13 & 12 & 11 & 13 & 13 & 18 & 12 & 13 & 12 & 17 & 22 & 13 \\
\hline & SK & 0 & 0 & 11 & 0 & 0 & 0 & 0 & 10 & 0 & 0 & 0 & 0 & 0 & 0 & 0 \\
\hline & SK+TE & 12 & 14 & 15 & 11 & 12 & 12 & 13 & 15 & 16 & 18 & 12 & 11 & 24 & 12 & 12 \\
\hline \multirow{4}{*}{ 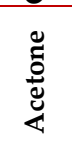 } & FL & 15 & 19 & 17 & 19 & 17 & 20 & 15 & 17 & 15 & 17 & 19 & 18 & 20 & 21 & 18 \\
\hline & FL+TE & 26 & 28 & 34 & 23 & 15 & 29 & 19 & 16 & 31 & 26 & 21 & 27 & 26 & 28 & 31 \\
\hline & SK & 15 & 12 & 15 & 14 & 12 & 15 & 19 & 17 & 15 & 15 & 14 & 16 & 15 & 15 & 16 \\
\hline & $\mathrm{SK}+\mathrm{TE}$ & 31 & 29 & 16 & 11 & 26 & 19 & 17 & 19 & 33 & 29 & 18 & 24 & 18 & 19 & 21 \\
\hline \multirow{5}{*}{ 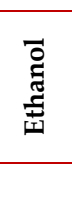 } & FL & 19 & 21 & 22 & 20 & 24 & 18 & 19 & 23 & 23 & 22 & 20 & 22 & 25 & 21 & 20 \\
\hline & FL+TE & 27 & 31 & 35 & 29 & 33 & 31 & 23 & 37 & 31 & 27 & 36 & 32 & 41 & 28 & 36 \\
\hline & SK & 16 & 22 & 19 & 19 & 21 & 22 & 20 & 19 & 22 & 20 & 23 & 21 & 20 & 21 & 19 \\
\hline & SK+TE & 36 & 34 & 31 & 28 & 29 & 28 & 24 & 39 & 27 & 35 & 29 & 28 & 27 & 28 & 31 \\
\hline & $\begin{array}{l}\text { Tetracy- } \\
\text { cline (TE) }\end{array}$ & 12 & 11 & 17 & 12 & 13 & 12 & 13 & 10 & 16 & 11 & 11 & 12 & 17 & 13 & 11 \\
\hline
\end{tabular}

Note: Tetracycline (TE) as a positive control; ${ }^{*}$ Data are mean of two replicates; (FL-Flower; SK-Seed kernel).

of 12-19 mm; which was increased to 11-33 mm after interaction with tetracycline. Flower extract in combination with tetracycline showed increase in IZD to $23-37 \mathrm{~mm}$. The results obtained with flower combination demonstrate that four isolates found to be synergistically sensitive to flower to a greater extent with the remarkable increase in zone of inhibition by 1-8 $\mathrm{mm}$. The combination seed kernel extract and tetracycline demonstrated effective synergistic activity against ST-1and ST-8 isolates with the increased IZD value of 8 and $10 \mathrm{~mm}$, respectively. However, partial synergistic effect was observed against ST-2, ST-10 and ST-15 isolates.

\section{Isolation and characterization of antioxidant and antisal- monella compounds \\ TLC analysis}

For isolation and identification of bioactive compounds, five different extracts were selected on the basis of their remarkable antisalmonella and antioxidant activity. TLC plate was developed using different solvent systems such as hexane: ethyl acetate, chloroform: methanol, petroleum ether: ethanol; ethanol: water: acetone. Among all the solvent systems used chloroform: methanol $(8: 2)$ was used as eluent for achieving greatest degree of separation of active compounds from acetone leaf, acetone flower, ethanol seed and ethanolic flower extracts. However, TLC plate loaded with P.E. seed extract was developed using hexane: ethyl acetate (9:1) solvent system. The Rf values of separated components on TLC plates were calculated by dividing the distance travelled by the compound of interest with the distance travelled by the solvent front. The developed TLC plates sprayed with DPPH were examined for yellow bands on a purple background representing compounds with antioxidant activity. However, bioautography plates were observed for regions of growth inhibition corresponding to compounds with antisalmonella compounds.

The calculated $\mathrm{Rf}$ values for acetonic flower extract showed the peaks at Rf values in range of 0.17-0.97. Ethanolic seed and flower extracts showed the peak at Rf value in the range of $0.24-0.85$ and $0.10-0.95$, respectively.
Whereas in case of P.E. seed extract Rf value was found in the range of 0.51-0.78. Maximum five components were observed in acetone flower extract, 5 components in ethanol flower extract, 3 in ethanol seed and 2 in a P.E. seed extract.

\section{TLC based antioxidant assay}

All the tested extracts showed antioxidant ability but number of active compounds was varied. The components with antioxidant activity were detected at different $\mathrm{Rf}$ values in acetone flower $(0.44$ and 0.87$)$, ethanol seed $(0.24$ and 0.85$)$, ethanol flower (0.10 and 0.72) and P.E. seed kernel (0.51 and 0.78$)$ extracts.

\section{TLC based Bioautography}

The antibiogram assay showed significant inhibitory activity against tested Salmonella typhi isolate (ST-1). Among the four tested extracts, the entire extracts viz. acetone flower, ethanol flower, ethanol seed and petroleum ether seed showed varying number of antisalmonella components. In acetone flower extract antisalmonella compounds were detected at Rf value of $0.17,0.68$ and 0.87 ; ethanol seed (0.85); ethanol flower (0.10 and 0.72); P.E. seed (0.78). Maximum 03 antisalmonella components were detected in acetone flower extract.

The portion of respective Rf values showing both antioxidant and antimicrobial activity were scrapped and analyzed for the compound identification.

\section{GC-MS analysis}

The fraction with dual activity of antioxidant and antisalmonella was subjected to GC-MS analysis for the identification of compounds. The results of GC-MS analysis revealed that the four different compounds with dual property of antioxidant and antisalmonella potential were found to be present in Mangifera indica L. flower and seed kernel extracts (Figure 1-4).

The compound viz. 1,2-Benzenedicarboxylic acid, isodecyl octyl ester was detected in acetonic extract of flower, while compound $1 \mathrm{~h}$-cycloprop e azulene was recorded in 


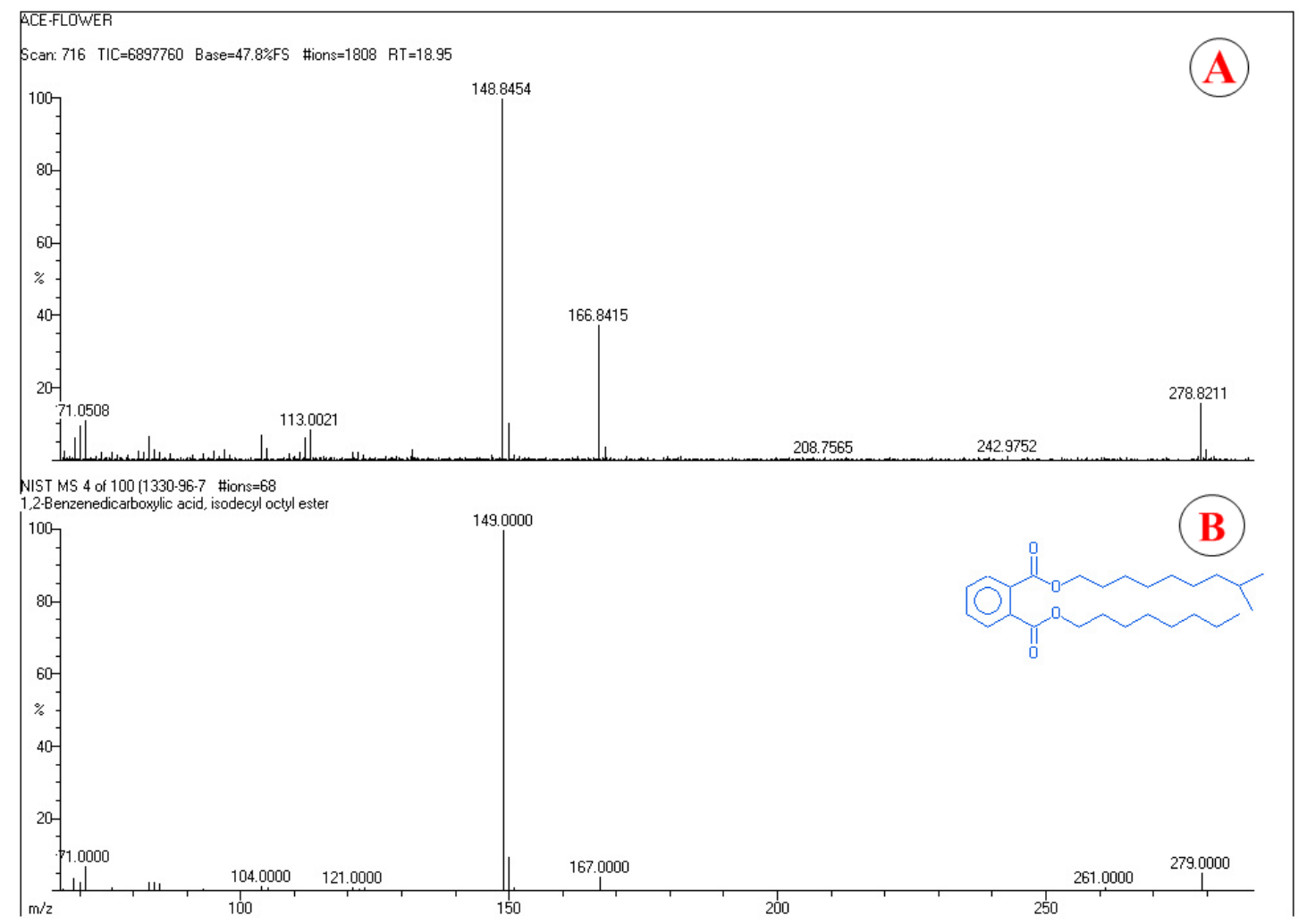

Figure 1: Total ion chromatogram (A) and mass spectrum (B) compound (1,2-Benzenedicarboxylic acid, isodecyl octyl ester) identified in acetonic flower extract of Mangifera indica $\mathrm{L}$.

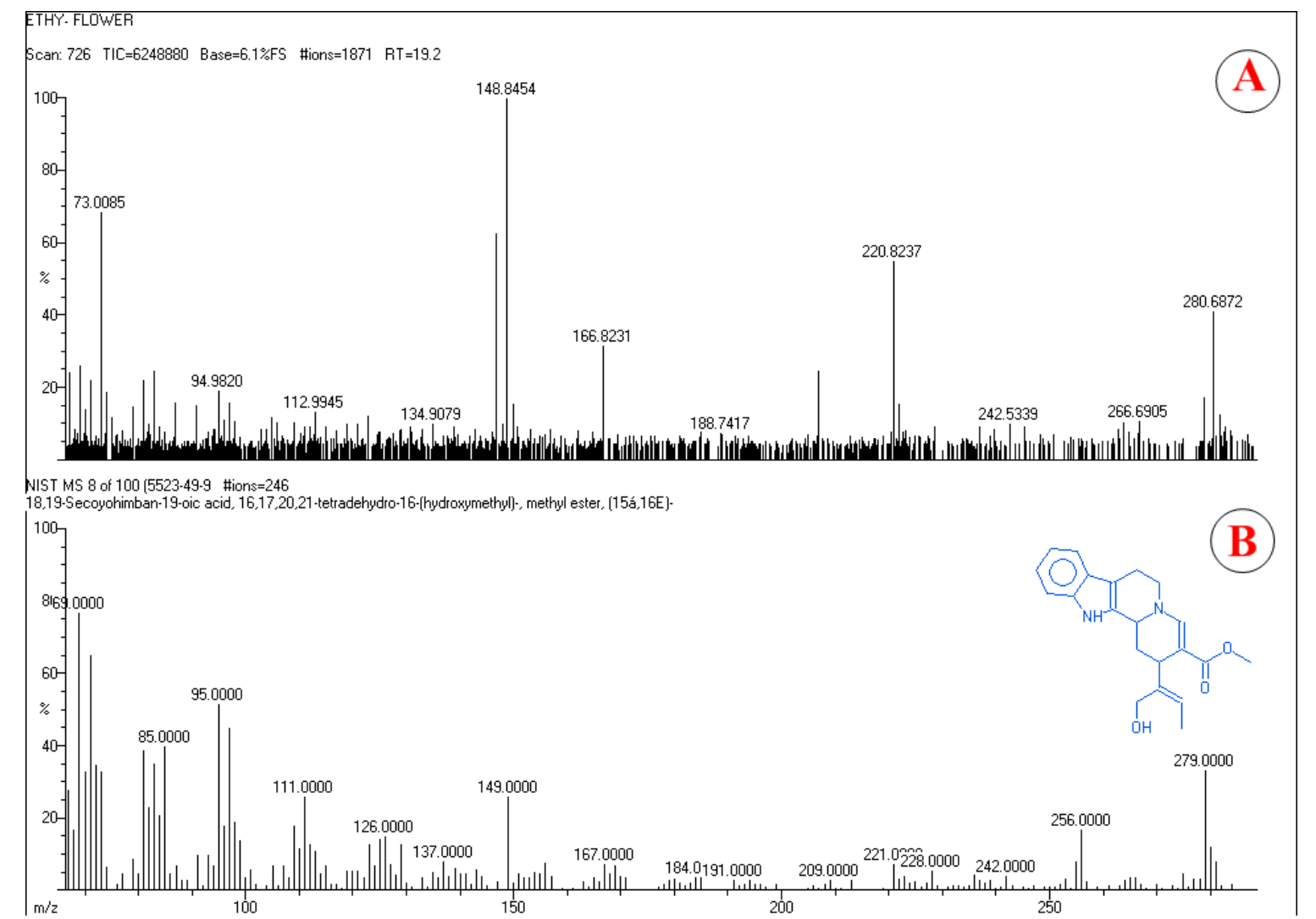

Figure 2: Total ion chromatogram (A) and mass spectrum (B) of compound (15ß)-20,21-Didehydro-16 $\beta$-(hydroxymethyl)-18,19-secoyohimban-19-oic acid methyl ester) identified in ethanolic flower extract. 


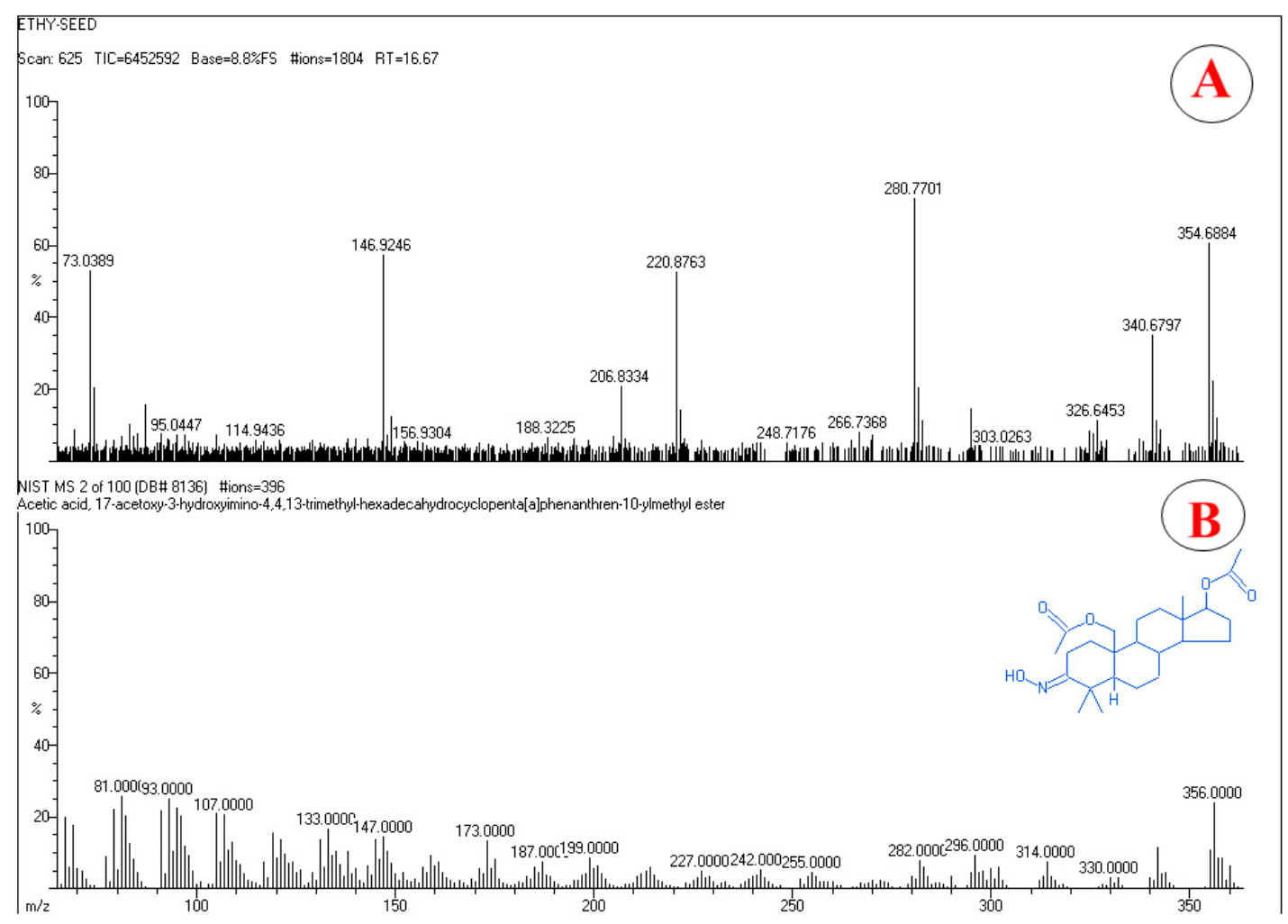

Figure 3: Total ion chromatogram (A) and mass spectrum (B) of compound (Acetic acid,17-acetoxy-3-hydroxyimino-4,4,13-trimethylhexadecahydrocyclopenta[a]phenanthren-10-ylmethyl ester) identified in ethanolic seed kernel extract of Mangifera indica $\mathrm{L}$.

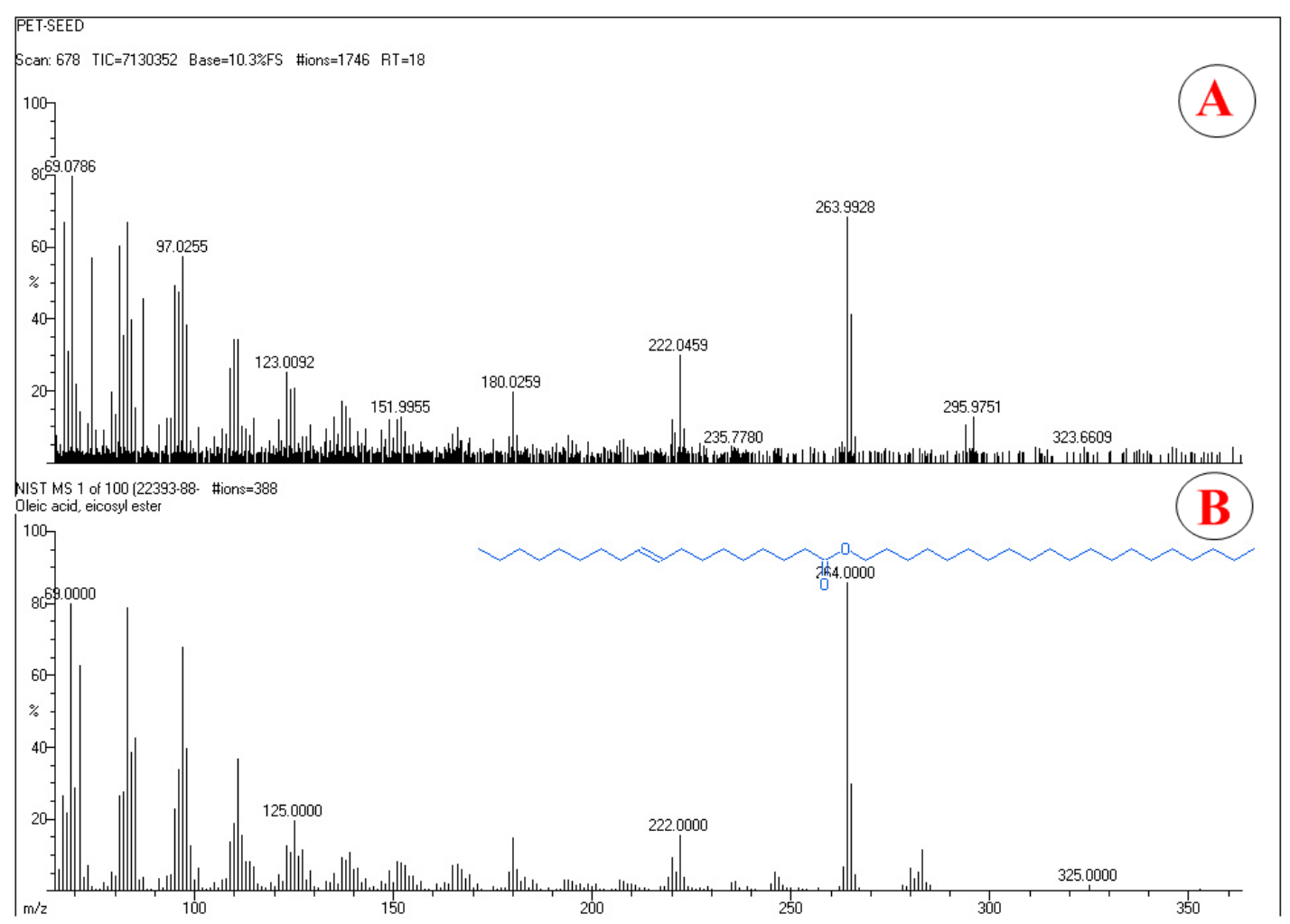

Figure 4: Total ion chromatogram (A) and mass spectrum (B) of compound (Oleic acid, eicosyl ester) identified in petroleum ether seed extract. 
acetonic extract of leaf. The compound with antisalmonella and antioxidant activity from the ethanolic flower extract was characterized as (15 $\beta$ )-20,21-Didehydro-16 $\beta$-(hydroxymethyl)-18,19-secoyohimban-19-oic acid methyl ester. In the ethanolic extract of seed kernel compound Acetic acid, 17-acetoxy-3-hydroxyimino-4,4,13-trimethylhexadecahydrocyclopenta[a]phenanthren-10-ylmethyl ester was identified as novel compound with antisalmonella and antioxidant capability. However, the compound responsible for exhibiting strong antioxidant and antisalmonella effect in petroleum ether extract of seed kernel was identified as Oleic acid, eicosyl ester. These compounds may have a major contribution in exhibiting significant antisalmonella and antioxidant activity.

\section{DISCUSSION}

Phenolic compounds are known for exhibiting antioxidant activity on the basis of their structure, number of hydroxyl groups and their distribution in the structure (Heo et al., 2007). In the present study, acetone and ethanol solvent extracts showed maximum capacity to extract the phenolic compounds than chloroform and petroleum ether solvents. These observations are in agreement with the findings of Chavan and Amarowicz, 2013. Phenols and flavonoids have been documented for exhibiting antioxidant effect (Yang et al., 2015). The present results of phenolic content of Mangifera indica L. showed more or less agreement with results of other studies (Puravankara et al., 2000; Soong and Barlow, 2006).

The group of phytochemicals, flavonoids is a broad class of plant phenolics that are known to have a well-recognized protecting ability against membrane lipoperoxidative damages (Cordova et al., 2002). The flavonoid content of Mangifera indica L. was reported in earlier studies and found to be more or less correlating with our findings (Abdul Aziz et al., 2011). Kim et al., (2010) reported the flavonoid content at the concentration of $8.15 \mathrm{mg} / \mathrm{g}$ in unripe mango flesh, $22.2 \mathrm{mg} / \mathrm{g}$ in unripe mango peel, 3.30 $\mathrm{mg} / \mathrm{g}$ in ripe mango flesh and $21.2 \mathrm{mg} / \mathrm{g}$ in ripe mango peel. In our study ethanolic extract of flower showed the flavonoid content of $36.0 \mathrm{mg} / \mathrm{g}$ of dry sample. It reveals that flavonoid content is more in flower as compared to unripe and ripe mango fruit.

Human body requires a number of minerals in order to maintain good health and need to consume relatively large amounts of carbohydrates, proteins, and lipids; small amounts of macro-elements; and trace amounts of microelements ( $\mathrm{Fe}, \mathrm{Zn}, \mathrm{Cu}, \mathrm{I}$, and $\mathrm{Se}$ ) and vitamins (Welch and Graham, 2004). Abulude et al. (2006) recorded mineral content of Mangifera indica seed and reported to contains $\mathrm{Zn}$ at the concentration of $93.50 \mathrm{mg} / \mathrm{kg}, \mathrm{Fe}(92.80 \mathrm{mg} / \mathrm{kg}), \mathrm{Cu}(4.20$ $\mathrm{mg} / \mathrm{kg}), \mathrm{Mn}(30 \mathrm{mg} / \mathrm{kg})$ and $\mathrm{Pb}(1.2 \mathrm{mg} / \mathrm{kg})$. Whereas in our study mineral content found at the concentration of $\mathrm{Cu}$ $(8.38 \mathrm{mg} / \mathrm{kg}), \mathrm{Fe}(660.50 \mathrm{mg} / \mathrm{kg}), \mathrm{Mn}(15.50 \mathrm{mg} / \mathrm{kg}), \mathrm{Pb}(1.89$ $\mathrm{mg} / \mathrm{kg})$ and $\mathrm{Zn}(11.81 \mathrm{mg} / \mathrm{kg})$. Mineral diversity in Mangifera indica $L$. may be due to the different geographical origin of plant. Seed kernel from Mangifera indica L. was appeared to be important source of iron $(\mathrm{Fe})$ with the concentration of $660.50 \mu \mathrm{g} \mathrm{g}^{-1}$.

Mangifera indica L., seed kernel and flower was found to be the efficient source of antioxidants that could be exploited in many foods to fight the oxidative process that can cause damage to many cells in our body. The strong antioxidant efficacy of seed kernel could be attributed to the presence of free radical scavenger components. These results are more or less in agreements with the observations of Pereira and Meireles, (2007). There are some other reports documented on antioxidant activity of Mangifera indica L. (Palafox-Carlos et al., 2012; Soong and Barlow, 2006).

Petroleum ether extracts were found to be most effective antisalmonella agent against MDR Salmonella typhi isolates, followed by ethanol, acetone and chloroform extracts. The antisalmonella effectiveness of P.E. extracts of flower and seed kernel against MDR Salmonella typhi isolates may be due to the presence of bioactive compounds, which were extracted in petroleum ether solvent during Soxhlet extraction. Antimicrobial activity of Mangifera indica L. have been previously discussed by many researchers (Sahrawat et al., 2013; Doughari and Manzara, 2008; Koleosho et al., 2013). Koleosho et al., (2013) reported the antimicrobial activity of Mangifera indica Linn. on Salmonella typhi. They noted the broad spectrum of an antibacterial activity of crude extract of Mangifera indica L. against Salmonella typhi. In present study, Mangifera indica L. flower was found to be the most potent extract in inhibiting the growth of most of MDR Salmonella typhi isolates with the efficient MIC value of $8 \mathrm{mg} / \mathrm{ml}$.

The combination activity of Mangifera indica L. extracts with antibiotic showed synergistic, additive and antagonistic effects. These results are in agreement with the findings of Olayinka et al., (2011) who showed the synergy between the extract and antibiotics and demonstrated the potential of $A$. africana as a source of antibiotic resistance modulating compounds.

The compound viz. 1,2-Benzenedicarboxylic acid, isodecyl octyl ester (Synonym: Phthalic acid) was detected in acetonic extract of flower. Similar compound phthalic acid ester 1,2-benzenedicarboxylic acid bis (2S-methyl heptyl) ester (1) was isolated from the hexane extract of the whole plant of Ajuga bracteosa (Singh et al., 2006) and Abirami and Rajendran, (2012) also reported the same compound in methanol extracts of Vernonia cinerea. The compound with antisalmonella and antioxidant activity from the ethanolic flower extract was characterized as (15 $\beta)$-20,21-Didehydro16 $\beta$-(hydroxymethyl)-18,19-secoyohimban-19-oic acid methyl ester (Synonym: Tetrahydrovallesiachotamine; indole alkaloid). Indole alkaloids and their cytotoxic, antibacterial and antifungal activities were reported by Zhang et al., (2014).

In the ethanolic extract of seed kernel compound Acetic acid, 17-acetoxy-3-hydroxyimino-4,4,13-trimethylhexadecahydrocyclopenta[a]phenanthren-10-ylmethyl ester was identified as novel compound with antisalmonella and antioxidant capability. This compound is chemically phytosterol. Guedes et al., (2014) reported the isolation of phytosterols of Dalbergia ecastophyllum (L.) Taub. (Leguminosae) and modulation of antibiotic resistance by a possible membrane effect. In the present study synergistic activity of ethanolic extract of seed kernel could be attributed this compounds. However, the compound responsible for exhibiting strong antioxidant and antisalmonella effect in petroleum ether extract of seed kernel was identified as Oleic acid, eicosyl ester. This bioactive compound was reported earlier by Albinjose et al., (2015) in Tinospora cordifolia by gas chromatography-mass spectrometry (GCMS). The compound Oleic acid, eicosyl ester from petroleum ether extract have been reported for exhibiting properties like anti-inflammatory, cancer preventive, dermatitigenic, hypocholesterolemic, anemiagenic and insectifuge (Sheela and Uthayakumari, 2013). To our knowledge for the first time, these compounds are reported in the Mangifera indica L. which are found to be truly novel antioxidant and antisalmonella compounds. These compounds could be exploited for treating the oxidative stress and infection caused by Salmonella typhi. 


\section{CONCLUSION}

Mangifera indica L. found to be a prominent source of phytochemicals when studied different parts of it. Mangifera indica L. was found to be abundant in total phenolic content and total flavonoid content. The significant amount of micro and macro-element $(\mathrm{Cr}, \mathrm{Cu}, \mathrm{Fe}, \mathrm{Zn}, \mathrm{B}, \mathrm{Na}$ and $\mathrm{K})$ were detected in different parts of Mangifera indica L. Seed kernel and flower extracts of Mangifera indica L. demonstrated significant antioxidant activity. Positive correlation was observed between antioxidant activity and TPC and TFC of Mangifera indica L. flower and seed kernel. The petroleum ether extracts of Mangifera indica L. were found to be most effective antisalmonella agent against MDR Salmonella typhi isolates, followed by ethanol, acetone and chloroform extracts. Combination study of petroleum ether extracts demonstrated multiple interaction effects with tetracycline; from synergism to antagonism. The seed kernel found to be more effective in showing synergistic activity than flower extract in combination with tetracycline. The synergistic effect of Mangifera indica L. extracts against most of the MDR isolates of Salmonella typhi clearly indicates that Mangifera indica L. may contains some sort of resistance modifying compounds. The selected active extracts viz. acetone flower, ethanol flower, ethanol seed kernel and petroleum ether seed kernel showed the presence of bioactive compounds. Our findings demonstrated that the presence of bioactive compounds like fatty acids esters, phytosterols and indole alkaloids in Mangifera indica L. were solely responsible for exhibiting antioxidant and antisalmonella properties. These compounds can be considered promising future source of antioxidant and antisalmonella agents in Mangifera indica L. plant.

\section{ACKNOWLEDGEMENT}

The authors thank the Dr. Krushnaraj for sharing their knowledge and Jayagen Biologics, Chennai for providing GC-MS analysis and 16S rRNA sequencing facilities and services. Ms. Dipali O. Somkuwar wants to acknowledge University Grant Commission (UGC) New Delhi, India for providing financial support by Rajiv Gandhi National Fellowship Scheme (RGNF) for Ph. D. Programme.

\section{REFERENCES}

Abdul Aziz, N., Wong, L., Bhat, R., Hoong, C.L. (2011). Evaluation of processed green and ripe mango peel and pulp flours (Mangifera indica var. Chokanan) in terms of chemical composition, antioxidant compounds and functional Properties. Journal of the Science of Food and Agriculture, 557-563. [DOI]

Abirami, P. and Rajendran, A. (2012). GC-MS analysis of methanol extracts of Vernonia cinerea. European Journal of Experimental Biology, 2(1): 9-

Abulude, F.O., Eluyode, O.S., Adesanya, W.O., Elemide, O.A. and Koumah, T. (2006). Proximate and selected mineral compositions of Mangifera indica and Persia americana seeds found in Nigeria. Agricultural Journal, 1: 72-76.

Albinjose, J., Jasmine, E., Selvankumar, T. and Srinivasakumar, K.P. (2015). Bioactive compounds of Tinospora cordifolia by gas chromatographymass spectrometry (GC-MS). International Journal of Multidisciplinary Research and Development, 2(1): 88-97.

Arogba, S. S. (2000). Mango (Mangifera indica) kernal: Chromatographic analysis of the Tannin, and stability study of the associated polypheno oxidase activity. Journal of Food Composition and analysis, 13(2): 149156. [DOI]

Chandel, D. S., Chaudhry, R., Dhawan, B., Paudey, A. and Dey, A. B. (2000). Drug-resistant Salmonella enterica serotype Paratyphi A in India. Emerging infectious Diseases, 6(4): 420-421. [DOI]

Chavan, U.D. and Amarowicz, R. (2013). Effect of various solvent systems on extraction of phenolics, tannins and sugars from beach pea (Lathyrus maritimus L.). International Food Research Journal, 20(3): 11391144.
Clinical and Laboratory Standards Institute, (2009). Methods for dilution antimicrobial susceptibility tests for bacteria that grow aerobically. Approved standard, 8th ed. CLSI publication M07-A8. Clinical and Laboratory Standards Institute, Wayne, PA.

Cordova, C.A.S., Siqueira, I.R., Netto, C.A., Yunes, R.A., Volpato, A.M., Filho, V.C., Curi-Pedrosa, R., Creczynski-Pasa, T.B. (2002). Protective properties of butanolic extract of the Calendula officinalis L. (marigold) against lipid peroxidation of rat liver microsomes and action as free radical scavenger. Redox Report, 7(2): 95-102. [DOI]

Crump, J.A., Luby, S.P. and Mintz, E.D. (2004). The global burden of typhoid fever. Bull. World Health Organization, 82: 346-353.

Davies, J. and Davies, D. (2010). Origins and Evolution of Antibiotic Resistance. Microbiology and Molecular Biology Reviews, 74(3): 417-433. [DOI]

Doughari, J.H. and Manzara, S. (2008). In vitro antibacterial activity of crude extract of Mangifera indica Linn. African Journal of Microbiological Research, 2: 067-072.

Emeruwa, A.C. (1991). The conservation of medicinal plants. Journal of Natural Products, 45(2): 123-127. [DOI]

Emine, N.H. and Salih, G. (2010). Total antioxidant capacity and total phenol contents of selected commercial fruit juices in Turkey. International Journal of Food Properties, 13(6): 1373-1379. [DOI]

Essawi, T. and Srour, M. (2000). Screening of some Palestinian medicinal plants for antibacterial activity. Journal of Ethnopharmacology, 70 (3): 343-349. [DOI]

Fernandez Ponce, M.T., Casas, L., Mantell, C. and Martinez De La Ossa, E.J. (2013). Potential use of mango leaves extracts obtained by high pressure extraction technologies in cosmetic, pharmaceutics and food industries. Chemical Engineering Transactions, 32: 1147-1152.

Girgis, N.I., Butler, T., Frenck, R.W., Sultan, Y., Brown, F.M., Tribble, D. and Khakhria, R. (1999). Azithromycin versus ciprofloxacin for treatment of uncomplicated typhoid fever in a randomized trial in Egypt that included patients with multidrug resistance. Antimicrobial Agents and Chemotherapy, 43: 1441-1444.

Guedes, G.M.M., Albuquerque, R.S., Soares-Maciel, R.S, Freitas, M.A Silva, V.A., Lima, E.O., Lima, M.A., Cunha, E.V.L. and Coutinho, H.D.M. (2014). Isolation of phytosterols of Dalbergia ecastophyllum (L.) Taub. (Leguminosae) and modulation of antibiotic resistance by a possible membrane effect. Arabian Journal of Chemistry, (Article in Press). [DOI]

Heo, H., Kim, Y., Chung, D. and Kim, D. (2007). Antioxidant capacities of individual and combined phenolics in a model system. Food Chemistry, 104(1): 87-92. [DOI]

Hugo, W.B. and Russel, A.D. (1984). Pharmaceutical Microbiology, Blackwell Scientific Publications, Third edition pp. 179-200.

Huo, J.Z. (2003). Determination of major and minor elements in the roots stems and leaves of chicory by the ICP-AES method. Chinese Journal of Analytical Chemistry, 31: 640-640.

Iwu, M.W., Duncan, A.R. and Okunji, C.O. (1999). New antimicrobials of plant origin. In: Janick J, eds., Perspectives on New Crops and New Uses. Alexandria, VA, ASHS Press, pp. 457-462.

Jain, N. and Sharma, M. (2003). Broad spectrum antimycotic drug for the treatment of ringworm infection in human beings. Current Science, 85: 30-34.

Jesudason, M.V. and John, T.J. (1992). Plasmid mediated multidrug resistance in Salmonella typhi. Indian Journal of Medical Research, 95: 6667.

Kadhiravan, T., Wig, N., Kapil, A., Kabra, S.K., Renuka, K. and Misra, A. (2005). Clinical outcomes in typhoid fever: adverse impact of infection with nalidixic acid-resistant Salmonella typhi. BMC Infectious Diseases, 5(1): 37. [DOI]

Kamble, V., Somkuwar, D. and Wankhade, S. (2016). Prevalence and antibiotic susceptibility profiling of Salmonella typhi from typhoid patients in Amravati city (Maharashtra) India. International Journal of Current Research, 8(1): 25683-25688.

Khan, R., Islam, B., Akram, M., Shakil, S., Ahmad, A., Ali, S.M., Siddiqui, M. and Khan, A.U. (2009). Antimicrobial activity of five herbal extracts against multi drug resistant (MDR) strains of bacteria and fungus of clinical origin. Molecules, 14(2): 586-597. [DOI]

Kim, D.M., Neupane, G.P., Jang, S.J., Kim, S.H. and Lee, B.K. (2010). In vitro efficacy of the combination of ciprofloxacin and cefotaxime against nalidixic acid-resistant Salmonella enterica serotype Typhi. International Journal of Antimicrobial Agents, 36(2): 155-158. [DOI]

Klancnik, A., Piskernik, S., Jersek, B. and Mozina, S.S. (2010). Evaluation of diffusion and dilution methods to determine the antibacterial activity of plant extracts. Journal of Microbiological Methods, 81(2): 121-126. 
Koleosho, A.T., Jose, A.R., Oyibo, P.G., Roland-Ayodele, M.A. and Uloko Mabel, E. (2013). Antimicrobial activity of Sphenocentrum jollyanum and Mangifera indica Linn. on Salmonella typhi. IOSR Journal of Pharmacy and Biological Sciences, 5(3): 50-54.

Kurahashi, N., Inoue, M., Iwasaki, M., Tanaka, Y., Mizokami, M. and Tsugane, S. (2009). Vegetable, fruit and antioxidant nutrient consumption and subsequent risk of hepatocellular carcinoma: a prospective cohort study in Japan. British Journal of Cancer, 100(1): 181-184. [DOI]

Ledesma, N., Campbell, C.W. and Campbell, R.J. (2002). Delicious Most World's the Growing Mangos: Tropical Florida. Gables, Coral Garden, Tropical Fairchild Fruit. Mango. Resources, Human and Agriculture Tropical College Honolulu. Manoa, Hawaii. pp. 222-507.

Li, L., Wang, S., Chen, J., Xie, J., Wu, H., Zhan, R. and Li, W. (2014). Major antioxidants and in vitro antioxidant capacity of eleven mango (Mangifera indica L.) cultivars. International Journal of Food Properties, 17: 1872-1887. [DOI]

Lin, J.-Y. and Tang, C.-Y. (2007). Determination of total phenolic and flavonoid contents in selected fruits and vegetables, as well as their stimulatory effects on mouse splenocyte proliferation. Food Chemistry, 101(1):140-147. [DOI]

Madunagu, B.E., Ebana, R.U.B. and Ekpe, E.D. (1990). Antibacterial and antifungal activity of some medicinal plant of Akwa Ibom State. West African Journal of Biological and Applied Chemistry, 35: 25-30.

Mandal, S., Mandal, M.D. and Pal, N.K. (2012). Enhancing chloramphenicol and trimethoprim in vitro activity by Ocimum sanctum Linn. (Lamiaceae) leaf extract against Salmonella enterica serovar Typhi. Asian Pacific Journal of Tropical Medicine, 5(3): 220-224. [DOI]

Olayinka, A., Adekanmi, A., Sunday, O., David, A. and Anthony, O. (2011). Interactions of antibiotics and methanolic crude extracts of Afzelia africana (Smith.) against drug resistance bacterial isolates. International Journal of Molecular Sciences, 12: 4477-4487.

Owuor, B., Chege, J., Orwas, C., Simons, A.J., Salimm, A.S. and Mutua, A. (2002). World Agroforestree database. Nairobi Centre, Kenya. (http://www.worldagroforestrycentre.org)

Palafox-Carlos, H., Yahia, E.M. and González-Aguilar, G.A (2012). Identification and quantification of major phenolic compounds from mango (Mangifera indica, cv. Ataulfo) fruit by HPLC-DAD-MS/MS-ESI and their individual contribution to the antioxidant activity during ripening. Food Chemistry, 135(1): 105-111. [DOI]

Pereira, C.G. and Meireles, M.A.A. (2007). Evaluation of global yield, composition, antioxidant activity and cost of manufacturing of extracts from lemon verbena (Aloysia triphylla L'herit. Britton) and mango (Mangifera indica L.) leaves. Journal of Food Process Engineering, 30(2): 150-173. [DOI]

Puravankara, D., Boghra, V. and Sharma, R. (2000). Effect of antioxidant principles isolated from mango (Mangifera indica $\mathrm{L}$ ) seed kernels on oxidative stability of buffalo ghee (butter-fat). Journal of Science and Food Agriculture, 80(4): 522-526. [DOI]

Rowe, B., Ward, L.R. and Threlfall, E.J. (1997). Multidrug resistant Salmonella typhi: a worldwide epidemic. Clinical Infectious Diseases, 24 (suppl. 1): S106-S109. [DOI]

Sahrawat, A., Pal, S. and Shahi, S.K. (2013). Antibacterial activity of Mangifera indica (mango) leaves against drug resistant bacterial strains. International Journal of Advanced Research, 1(6): 82-86.

Schiber, A., Berardini, N. and Carle, R. (2003). Identification of flavonol and xanthol glycosides from mango peels by HPLC. Journal of Agricultural and Food Chemistry, 51: 5006-5011.
Sheela, D. and Uthayakumari, F. (2013). GC-MS Analysis of bioactive constituents from coastal sand dune taxon - Sesuvium portulacastrum (l) Bioscience Discovery, 4(1): 47-53.

Singh, N., Mahmoody, U., Kaul, V. K. and Jirovetzz, L. (2006). A new phthalic acid ester from Ajuga bracteosa. Natural Product Research, 20(6): 593-597.

Singleton, V.L. and Rossi, J.A. (1965). Colorimetry of total phenolics with phosphomolybdic-phosphotungstic acid reagents. American Journal of Enology and Viticulture, 16: 144-158.

Somkuwar, D.O. and Kamble, V. A. (2013). Phytochemical screening of ethanolic extracts of stem, leaves, flower and seed kernel of Mangifera indica L. International Journal of Pharma and Biosciences, 4(2): 383-389.

Soong, Y.Y. and Barlow, P.J. (2006). Quantification of gallic acid and ellagic acid from longan (Dimocarpus longan Lour.) seed and mango (Mangifera indica L.) kernel and their effects on antioxidant activity. Food Chemistry, 97(3): 524-530. [DOI]

Tsuda, T., Shiga, K. and Ohshima, K. (1996). Inhibition of lipid peroxidation and active oxygen radical scavenging effect of anthocyanin pigments isolated from Phaselous vulgaris L. Biochemical Pharmacology, 52(7): 1033-1039. [DOI]

Višnja, K., Sonja, S.M., Ivana, G., Danijela, S., Ivica, L. and Anja, K. (2013). Phenolic profile, antioxidant capacity and antimicrobial activity of leaf extracts from six Vitis vinifera L. varieties. International Journal of Food Properties, 16(1): 45-60. [DOI]

Von Gadow, A., Joubert, E. and Hansmann, C.F. (1997). Comparison of antioxidant activity of aspalathin with that of other plant phenols of Rooibosed tea (Aspalathon linearis), $\alpha$-tocopherol, BHT and BHA. Journal of Agricultural and Food Chemistry, 45(3): 632-638. [DOI]

Wang, L., Xu, H.N., Yao, H.Y. and Zhang, H. (2011). Phenolic Composition and radical scavenging capacity of Vaccinium bracteatum Thunb. Leaves. International Journal of Food Properties, 14(4): 721-725. [DOI]

Welch, R.M. and Graham, R.D. (2004). Breeding for micronutrients in staple food crops from a human nutrition perspective. Journal of Experimental Botany, 55 (396): 353-364. [DOI]

Willcox, J.K., Ash, S.L. and Catignani, G.L. (2004). Antioxidant and prevention of chronic disease. Critical Reviews in Food Science and Nutrition, 44(4): 275-295. [DOI]

World Health Organization (2007). Typhoid Fever. Retrieved: 2007-08-28. [Link]

Wu, Y.W., Zhang, H., Hu, L., Chen, J. and Jiang, Z.C. (2003). Study on the leaching characteristics and speciation of $\mathrm{Cu}, \mathrm{Mn}$ and Ti in ginkgo leaves. Journal of Analytical Sciences, 19: 201-204.

Yang, M., Shen, Q., Li, L., Huang, Y. and Chung, H. (2015). Phytochemical profiles, antioxidant activities of functional herb Abrus cantoniensis and Abrus mollis. Food Chemistry, 177: 304-312. [DOI]

Zhang, L., Hua, Z., Song, Y. and Feng, C. (2014). Monoterpenoid indole alkaloids from Alstonia rupestris with cytotoxic, antibacterial and antifungal activities. Fitoterapia, 97: 142-147. [DOI]

Zheng, L., Chen, H., Han, X., Lin, W. and Yan, X. (2005). Antimicrobial screening and active compound isolation from marine bacterium NJ63-1 associated with the sponge Hymeniacidon perleve. World Journal of Microbiology and Biotechnology, 21(2): 201-206. [DOI] 